ISSN: $1130-3743$

\title{
UN ENFOQUE PEDAGÓGICO PARA EL DISEÑO DE PROGRAMAS DE FORMACIÓN EN CONTEXTOS ORGANIZATIVOS
}

\author{
A pedagogical perspective to design training programmes \\ in enterprise
}

Une approche pédagogique pour le dessin des programmes formatives dans contextes organisatives

\section{Carolina FERNÁNDEZ-SALINERO MIGUEL}

Universidad Complutense de Madrid. Facultad de Educación. Departamento de Teoría e Historia de la Educación. Edificio La Almudena. C/ Rector Royo Villanova, s/n. Ciudad Universitaria. 28040 Madrid. Correo-e: cfernand@edu.ucm.es

Fecha de recepción: marzo de 2004

Fecha de aceptación definitiva: octubre de 2004

BIBLID [(1130-3743) 16, 2004, 109-144]

RESUMEN

El diseño de un programa de formación es una labor de gestión del conocimiento dentro de las organizaciones que contempla tres metas fundamentales: generar el desarrollo y optimización organizativos, favorecer un adecuado clima de trabajo y potenciar las competencias personales, profesionales y laborales de las personas que conforman el equipo humano de la organización. Esta misión debe partir del Departamento de Recursos Humanos, Personal o Formación y ha de convertirse en una tarea organizativa habitual. En cuanto a la estructura de un programa de formación, resulta fundamental no olvidar la secuencia siguiente: concretar su denominación, ventajas e inconvenientes; detectar y priorizar las necesidades más relevantes; concebir la formación como objetivo estratégico; plantear las metas a alcanzar; programar operativamente los contenidos, las modalidades y el método; seleccionar a los formadores, controlar la organización (condiciones, lugares y tiempos), la duración, el presupuesto y los recursos; establecer las líneas 


\section{CAROLINA FERNÁNDEZ-SALINERO MIGUEL \\ UN ENFOQUE PEDAGÓGICO PARA EL DISEÑO DE PROGRAMAS DE FORMACIÓN EN CONTEXTOS ORGANIZATIVOS}

de ejecución, manteniendo un seguimiento constante del proceso; y evaluar el programa de manera continua. Un planteamiento de este tipo abre una puerta a la formación como instrumento de cambio y mejora y orienta la estrategia organizativa hacia el enfoque de la "organización autocualificante", aquella que busca en el conocimiento y en el aprendizaje las herramientas para el progreso y la competitividad.

Palabras clave: auditoría, competencias, evaluación de la formación, gestión de la formación, programa de formación, recursos humanos.

\section{SUMMARY}

A training programme is very important skill to knowledge management and it has three main aims: to develop enterprise, to get a good job place and to increase professional competences of human resources. All of this has to do Human Resources Department, Training Department or Personnel Department and it is very useful for enterprise. A training programme needs to know what are the best things and the worst things to design it, what are the training needs, what are the main objectives, what are the programme contents, strategy and methodology, what are the trainers and the organization (disposition, places, times, resources, money), how is the process and how are we going to evaluate the training programme. These ideas are good to improve enterprise and to become a "knowledge-creating company": an enterprise that use the knowledge to be more competitive.

Key words: audit, competences, human resources, training evaluation, training management, training programme.

\section{SOMMAIRE}

La conception d'un programme de formation est un travail de gestion de la connaissance dans les organismes qui contemple trois objectives principaux: promouvoir le développement et l'optimisation organisationnel, creer un climat favorable de travail et développer les compétences personnelles, professionnelles et du travail des individues qui conforment l'équipe humaine de l'organisation. Cette tâche doit partir du Département des Ressources Humaines, Personnel ou de la Formation, et devenir une tâche d'organisation habituelle. En ce qui concerne l'estructure d'un programme de formation, il est fondamentale ne pas oublier la sequence suivant: identifier la denomination, ses avantages et inconvénients; détecter et donner la priorité aux nécessités les plus excellentes; concevoir la formation comme un objective stratégique; soulever les buts à l'extension; programmer operationnelment le contenues, la stratégie et la méthodologie; la sélection des formateurs, le control de l'organisation (conditions, endroits et périodes), la durée, le budget et les ressources; pour établir les lignes de l'exécution, maintenant une poursuite constante du processus; et l'évaluation continue du programme. Une exposition de ce type ouvre une porte à la formation comme instrument de changement et d'amélioration et oriente stratégies d'organisation vers l'approche de al'autocualificante de organización", cela qui cherche dans la connaissance et l'apprentissage des outils pour le progrès et la compétitivité.

Mots clef: audit, compétences, évaluation de la formation, programme de formation, gestion de la formation, ressources humaines. 


\section{INTRODUCCIÓN}

Las nuevas tecnologías, los desafíos procedentes de la competitividad de los mercados o los cambios organizativos son algunos factores que hacen necesaria la formación continua de los efectivos de una organización. Pero, para ello, se requiere un estudio profundo de las necesidades y demandas de los recursos humanos y una asequible respuesta a las mismas desde la perspectiva formativa. No es una tarea imposible, sólo precisa de un conocimiento de la organización de referencia, un diagnóstico de necesidades real, la priorización de aquellas que verdaderamente generan problemas de funcionamiento en la compañía, eficazmente resueltos desde parámetros formativos y una consecuente programación de las estrategias, los recursos, los métodos y las personas que van a involucrarse en este proceso dinámico de cambio. No olvidando, desde luego, la evaluación tanto del proceso, como de los resultados obtenidos tras la iniciativa formativa.

Hay todo un campo de trabajo para la educación, rico, interesante y eficaz, que hace necesario conocer y emplear oportunamente técnicas, instrumentos, herramientas, conocimientos y creatividad. Descubrir estos elementos es lo que pretende este artículo, favoreciendo una aproximación clara, sencilla y rigurosa a todas las fases que debe recoger el diseño de un programa de formación. Todo ello, desde un enfoque pedagógico realista y sistemático que permita comprender el hecho de la formación en las organizaciones como un hecho educativo concreto y alcanzable desde perspectivas teórico-prácticas de la educación actual.

\section{Descubrir QUÉ ES Y PARA QUÉ SIRVE EL DISEÑo DE UN PROGRAMA DE FORMACIÓN}

Conviene incidir en primer lugar en la utilidad del diseño riguroso y específico de un programa de formación, para lo cual resulta imprescindible concretar la terminología precisa para llevar a cabo esta tarea.

\section{1. ¿En qué consiste un programa de formación?}

Un programa de formación es un proyecto de actuación en el que, a partir de la identificación de unas necesidades concretas, se realiza una previsión sistemática de objetivos, se definen estrategias para su consecución, seleccionándose los medios y recursos necesarios, y se especifican criterios de evaluación, rigurosos y realistas. Se inscribe, por lo tanto, dentro de una estructura general de planificación de la formación desarrollada por la compañía, donde un Plan de Formación se concreta como un documento elaborado por la dirección de la organización con la finalidad de asegurar la formación de su personal por un período determinado. El Plan se deriva, pues, de la política formativa de la organización y debe incluir: el público a quien va dirigido, los programas formativos necesarios, el presupuesto, 
CAROLINA FERNÁNDEZ-SALINERO MIGUEL

UN ENFOQUE PEDAGÓGICO PARA EL DISEÑO DE PROGRAMAS DE FORMACIÓN EN CONTEXTOS ORGANIZATIVOS

cómo se evaluará el grado de consecución de los resultados tras su aplicación y el impacto de todo ello en la dinámica general de la organización.

Según la conceptualización precedente, podemos considerar que el proceso de formación se divide en los siguientes momentos (Martínez Mut, 2002, 185):

- Política formativa. Está constituido por el conjunto de elementos que fundamentan y dan sentido y orientación al programa de formación. Participan en la gestión de esta fase las direcciones de las áreas o departamentos de la entidad, la Dirección de Formación y la propia Dirección de la empresa a través de sus líneas estratégicas para el período determinado. Una concreción de las decisiones de esta fase son los criterios de priorización de las necesidades formativas y la asignación de recursos personales y materiales a la gestión de programas.

- Ingeniería o diseño de la formación.,Es el momento de preparación o planificación en el que se establecen los compromisos entre los gestores que participan en el programa y se fijan las condiciones para que todos y cada uno de ellos puedan cumplir con sus funciones. Se deciden quiénes serán los formadores y demás gestores, cuáles son los objetivos del programa, los recursos necesarios y la orientación metodológica predominante, así como sus criterios de justificación.

- Realización o ejecución del programa. Es el momento pedagógico por excelencia, en el que el alumno cobra su especial protagonismo, siendo a la vez cliente y proveedor de una parte del proceso. La ordenación y utilización de los recursos y de las actividades en función de los objetivos y de la realidad de los participantes es una de las condiciones de garantía de la eficacia del programa, al mismo tiempo que la adecuada evaluación de los resultados producidos.

- Transferencia de lo aprendido. Es una de las medidas principales de la eficacia y de la eficiencia del programa. Trata de asegurar que se satisfacen las necesidades que dieron origen al programa concreto. Es el retorno de la energía importada en forma de "mejora de la realidad de la compañía, departamento, área, oficina o grupo de empleadosn.

\subsection{Pero, ¿qué se entiende por formación?}

El propósito de toda formación es el de capacitar a un individuo para que pueda realizar convenientemente una tarea o un trabajo determinados con "los requisitos pertinentes de calidad" (Sarramona, 2002, 19). La gestión de la calidad supone, por lo tanto, reconsiderar a la formación como un proceso o servicio, e introducir en su gestión el concepto de cliente, así como sus necesidades y expectativas. De ahí que su aplicación a los procesos formativos suponga obtener, en palabras de Martínez Mut (2002, 175), las siguientes consecuencias: 
CAROLINA FERNÁNDEZ-SALINERO MIGUEL

UN ENFOQUE PEDAGÓGICO PARA EL DISEÑO DE PROGRAMAS DE FORMACIÓN EN CONTEXTOS ORGANIZATIVOS

1. No deben diseñarse programas de formación desvinculados de las necesidades de los sujetos, clientes y gestores de su propio proceso formativo.

2. Los programas de formación deben considerarse inmersos en un sistema de intervención para satisfacer esas necesidades, en el cual son relevantes las funciones de asesoramiento o tutoría, denominadas también de mentorización o coaching.

3. La evaluación de la eficacia de la formación debe asegurarse utilizando procedimientos de recogida de información que permitan el feed-back y el feed-before constantes del sistema.

4. La eficiencia del sistema exige una evaluación a medio y largo plazo del cambio de comportamiento profesional o de la aplicación de las competencias individuales adquiridas y que se realice de manera tan objetiva y científica como la evaluación inmediata de cada actividad.

5. Para que la formación de las personas se considere una inversión se necesita la participación activa de los miembros de la organización y el compromiso por parte de los directivos de facilitar y reforzar la ejecución del nuevo comportamiento.

La formación se ha definido, en este sentido, como una estrategia organizativa, sistemática y programada destinada a habilitar para la realización de tareas progresivamente más complejas y responsables, a actualizar las competencias profesionales exigidas por el continuo desarrollo tecnológico y socioeconómico, al mismo tiempo que a lograr una mejora de la competencia personal, haciendo del trabajo una fuente de aprendizaje y de satisfacción para el trabajador. Los objetivos de la formación así entendida se proyectan en tres ejes fundamentales: de conocimientos (profesionales, de la propia organización y de su entorno social), de habilidades (cognitivas, comunicativas, manuales, técnicas) y de actitudes (hacia el trabajo y el aprendizaje, hacia la organización, hacia los otros y hacia sí mismo) (Sánchez Cerezo, 1991, 249-250).

Pero la transformación del contenido y de la organización del trabajo es hoy tan rápida que resulta necesario plantear una nueva estrategia de formación. Ya no basta con adquirir competencias, se debe dar paso a lo que Biolley ya nos adelantaba en 1992 y que el autor denomina "formación-exploración":

La formación-exploración se concibe esencialmente no para transmitir conocimientos, sino para comenzar a aprender la profesión de mañana. Es decir, para desarrollar a la vez un deseo, una percepción de la necesidad de hacerlo y un enfoque individual y colectivo de superación permanente del estado adquirido en un momento dado $(1992,217)$.

No obstante, un concepto de formación actual y realista debe ir más allá de esta primera fase y completarse con otros aspectos: 
- La experimentación. Cada persona debe situarse en una actitud de investigación y comprobación constante. Con la contrastación de sus teorizaciones y con la realidad podrá aprender y generar nuevos campos de exploración.

- El desarrollo personal. Sin identidad individual y cierto grado de autoestima es muy difícil que una persona pueda evolucionar al ritmo de las rápidas transformaciones sin consecuencias graves para su desequilibrio y, por lo tanto, para su desarrollo profesional.

- La multiculturalidad. No se trata de la pluralidad que pueda existir en el seno de una organización determinada, sino de la de una persona o grupo de personas que trabaja una parte del tiempo en su país y el resto en otros, con gente de otras nacionalidades y culturas. Necesariamente la formación debe ser intercultural, es decir, debe desarrollar las capacidades y las competencias imprescindibles para compartir experiencias profesionales y crear con otros individuos que tienen unos esquemas mentales y unas representaciones semánticas diferentes a las propias.

La formación entendida bajo estos términos va a ser el eje conceptual a través del cual articulemos el presente texto.

\section{3. ¿En qué tipo de organización se desarrolla formación?}

La organización actual tiende a ser un sistema social abierto e integrado que se encuentra sumergido en un entorno. Ese entorno está compuesto por todos los elementos sociales, políticos, económicos, axiológicos, etc., que integran nuestra actualidad. De ese entorno recibe una serie de inputs, en forma de materias primas, información, recursos financieros, tecnológicos y humanos. Estos recursos son utilizados o transformados por la propia organización, la cual devuelve una serie de outputs, consistentes en bienes y servicios. La organización participa, por consiguiente, de los principios y características de los sistemas abiertos: sinergia (el todo es superior a la suma de las partes); importación, transformación y exportación de energía e información; feedback, orden y buen funcionamiento (entropía negativa); estabilidad y homeostasis dinámica (tendencia al crecimiento y expansión equilibrados); diferenciación (especialización); equifinalidad (iguales fines desde posturas diversas) ${ }^{1}$.

La organización así concebida responde a lo que podemos denominar una organización inteligente, que se define como el sistema sociotécnico abierto que es capaz de aprender y, en consecuencia, de saber transformarse ${ }^{2}$. Se distinguen los procesos

1. Estas características varían en cierta medida en función de la simplicidad o complejidad de la estructura organizativa, del modelo estratégico en que se fundamente (más genérico o más especializado), de la cultura o sistema de valores en el que se apoye, de sus niveles jerárquicos. del tamaño y del sector de pertenencia.

2. Cuando nos referimos a transformación estamos hablando de la dinámica de cambio en la cual se ve sumergida la organización y que puede realizarse de tres formas: cambio reactivo 
de aprendizaje individual respecto de los organizativos. Los primeros responden a la formación profesional, al desarrollo de las competencias laborales de los trabajadores asociadas a un perfil profesional concreto, mientras que los segundos representan la consecuencia o los resultados del aprendizaje en equipo, de la búsqueda a través de las relaciones interpersonales de los fines organizativos comunes. Si seguimos a Senge (1992), la organización inteligente y, por lo tanto, sus procesos de aprendizaje se tienen que apoyar en cinco disciplinas o enfoques particulares: dominio personal y profesional de los trabajadores, sistema de razonamiento y de actuación de la organización, liderazgo compartido, aprendizaje en equipo e integración sistémica de las cuatro anteriores en un proyecto de organización común.

\section{LA ESTRUCTURA BÁSICA DE UN PROGRAMA DE FORMACIÓN}

Estamos ahora preparados para conocer las diferentes fases y elementos que conforman el diseño de un programa de formación, lo que pasamos a analizar a continuación.

\subsection{Detectar las necesidades de la organización}

El primer paso cuando se diseña un programa de formación es la detección y el análisis de las necesidades formativas. Estas necesidades provienen directamente del plan general de formación y del plan estratégico de la organización, ya que éstos proporcionan información sobre aquellos aspectos que la organización necesita para conseguir sus objetivos (Pineda, 1995, 34). Pero no deben alejarse de las percepciones de los propios trabajadores - actores protagonistas del proceso de formación-, quienes han de verse implicados en esta fase tan importante.

Existen actualmente dos perspectivas fundamentales, según Font e Imbernón (2002, 39-41), para poder conceptualizar las necesidades de formación:

- Una primera, más normativa y prescriptiva, que identifica la necesidad de formación como una carencia y la define como el índice de discrepancia entre dónde nos encontramos y hacia dónde queremos llegar. O lo que es lo mismo, la manifestación de las diferencias entre el perfil de exigencias del puesto y el perfil de competencias del individuo.

- Una segunda, más participativa, que considera a la necesidad de formación como un problema, como un juicio de valor que implica tener en cuenta tres cosas: hablar de los valores que tienen las personas, describir

\footnotetext{
(supervivencia), cambio proactivo (anticipación) y cambio creativo (provocación y liderazgo permanente). Esta tipología de cambios se encuentra aparejada a los objetivos de desarrollo organizativo, siendo los más comunes aumentar la cantidad, incrementar la calidad, disminuir los costes y optimizar la satisfacción del cliente y del personal.
} 
la población objeto y su entorno, así como identificar una posible solución para ese problema. En esta perspectiva se ve al empleado como sujeto de formación, introduciéndose los conceptos clásicos de necesidad sentida o percibida, expresada (a través de la demanda), relativa (la necesidad surge por comparación), analítica (la necesidad aparece sobre la base de la información disponible). Todas ellas se entremezclan y se manifiestan conjuntamente.

Ambas perspectivas conviven en el análisis de las necesidades de formación y son una muestra evidente de que los procesos de detección de necesidades en las organizaciones han evolucionado con el tiempo, en sintonía con los nuevos valores sociales y con la evolución de las propias culturas corporativas. Esta convivencia permite al planificador de la formación establecer un equilibrio entre las necesidades normativas y las participativas, esto es, entre las necesidades profesionales organizativas y las de desarrollo profesional personal.

Ya nos refiramos a una u otra perspectiva y bajo un punto de vista estratégico, se pueden distinguir dos tipos genéricos de necesidades de formación (Solé y Mirabet, 1997, 60-61): necesidades de formación reactivas (se deducen de la observación de problemas concretos y responden a necesidades formativas actuales y ciertas) y necesidades de formación proactivas (aquellos vacíos de formación que, si se acertara a cubrirlos, capacitarian al personal de la organización frente a la innovación).

La formación proactiva trata de anticiparse y responder a las exigencias del futuro. La formación reactiva trata de ofrecer soluciones formativas a los desajustes del presente.

Las necesidades de formación pueden también clasificarse según el ámbito funcional que se pretenda cubrir. En este caso, se habla de necesidad de formación vertical o de vacío de formación vertical cuando con los programas formativos se desea cubrir aspectos relativos a una competencia o a competencias asociadas a un perfil profesional concreto. A su vez, un programa formativo cubrirá una necesidad de formación borizontal cuando vaya a resolver deficiencias de competencias de diversos puestos de trabajo que no tienen por qué estar relacionados entre sí (Solé y Mirabet, 1997, 61-62).

La formación horizontal suele ser más proactiva que la formación vertical. La formación vertical suele tener un carácter más aplicado que la horizontal.

Finalmente, podemos hablar de micronecesidades de formación, que son aquellas que afectan a una sola persona o a una población muy reducida y que se derivan de situaciones de promoción, transferencia de puesto, planes de carrera, control de la calidad, accidentes de trabajo, conflictos laborales o proyectos de 
investigación y desarrollo. Y también podemos referirnos a las macronecesidades de formación, aquellas que afectan a un grupo importante de trabajadores, el cual generalmente pertenece a la misma categoría profesional (responsables, encargados, técnicos) y que proceden de los informes de la dirección, de la construcción de nuevas secciones, del lanzamiento de novedosos productos, de la compra de nuevos equipamientos, de cambios en la cultura corporativa o de novedosas políticas de la organización.

\subsubsection{Los ámbitos de estudio}

Pero, la detección de necesidades de formación no es suficiente para dar paso a la siguiente fase en el diseño del programa de formación. Es imprescindible analizar la adecuación de las necesidades detectadas a los diferentes elementos que integran la organización. Goldstein $(1986,27)$ plantea el análisis de necesidades en tres ámbitos de estudio:

1. Análisis de la organización. Se refiere al estudio de aquellos componentes del sistema organizativo que pueden afectar a los programas formativos que se adoptarán: objetivos estratégicos, factores internos (clima de la organización, cultura, normas), factores externos (entorno de la organización, mercado, competencia, legislación), recursos de la organización (humanos, materiales y funcionales).

2. Análisis del perfil de competencias. Consiste en el estudio detallado del puesto de trabajo en el que se ha detectado la necesidad de formación. Primero, se realiza una descripción del perfil del puesto de trabajo y, a continuación, se procede a la especificación de las competencias que lo integran, en términos de conocimientos, habilidades y actitudes requeridas.

3. Análisis de las personas y grupos implicados. Consiste en valorar el dominio real por parte de los trabajadores de las competencias exigidas por su puesto de trabajo.

Los resultados del análisis de las personas, contrastados con los del análisis de las competencias y el organizativo generan unas necesidades de formación específicas y concretas, a partir de las cuales resulta posible planificar la formación que les dé respuesta.

\subsubsection{Las técnicas para detectar las necesidades de formación}

Existen básicamente cinco procedimientos o técnicas para detectar las necesidades de formación en la organización:

1. La observación. El control y registro pormenorizado del día a día en la organización nos permite detectar fallos y errores que resultarían 

EN CONTEXTOS ORGANIZATIVOS

fácilmente subsanables por medio de un programa formativo (averías, accidentes, pérdidas de tiempo...).

2. Los grupos de formación. Autoanálisis en grupos homogéneos de personas, en los que a partir de un problema, el grupo plantea las ideas para el máximo rendimiento en el puesto de trabajo, exponiendo a continuación los conocimientos, habilidades o actitudes que se requieren para poner en práctica las ideas expresadas, fruto de la traducción del problema en la necesidad de formación descubierta.

3. El cuestionario. Puede dirigirse, bien a los futuros receptores de las acciones de formación, bien a los clientes de un servicio. Existen ciertas normas que deben seguir los cuestionarios (Puchol, 1995, 211): El anonimato (ausencia de datos personales y respuestas escritas), la motivación (implicación a través de la información), la técnica del embudo (empezar por preguntas muy sencillas y poco comprometedoras, continuar con preguntas "fuertes" y cerrar la batería con preguntas "Suaves"), la brevedad (preguntas estrictamente necesarias) y la comunicación posterior (informar sobre los resultados globales). En la elaboración de un cuestionario se debe huir, según Puchol (1995, 212), de preguntas dobles, formuladas de manera negativa, con respuesta sugerida, palabras rebuscadas, interpretaciones dobles, adverbios vagos (frecuentemente, normalmente), largas, abiertas (en detrimento de las cerradas más fáciles de codificar), fuertes, de carácter íntimo o planteadas en determinados momentos psicológicos (de especial tensión).

4. La entrevista. Permite profundizar en temas de interés y posibilita aclarar conceptos confusos. Además, el entrevistado puede expresar más abiertamente cuestiones que son de interés o preocupación para la realización de sus tareas. Es necesario, sin embargo, contrastar y complementar la información obtenida con otros instrumentos, adecuándola a las necesidades de la organización.

5. El análisis de la demanda formativa. Para ayudar a sistematizar y clarificar estas demandas, se deben destacar como aspectos básicos a explicitar por parte del detector de la necesidad los siguientes: descripción de la necesidad de formación y personas implicadas en la misma, indicadores de la situación actual, objetivos concretos de aprendizaje, así como la escala de medición del cambio para contrastar las diferencias entre el nivel de entrada de los participantes y los resultados obtenidos después del período de formación.

Las cinco técnicas analizadas son las más utilizadas en la detección de necesidades dentro de la organización y permiten obtener información pertinente para desarrollar adecuados programas formativos, aunque evidentemente no son las únicas, existiendo gran flexibilidad a la hora de utilizar procedimientos específicos para concretar carencias de formación. 


\subsubsection{Las fuentes de donde emanan las necesidades}

Otro elemento que resulta imprescindible controlar en el análisis de necesidades consiste en la precisión de las fuentes de donde emanan las mismas, que pueden ser: los objetivos estratégicos de la organización; la cultura, lo considerado como valioso en el desarrollo de la actividad organizativa; la innovación tecnológica provocada por la renovación de la maquinaria y las herramientas específicas; la reconversión de la organización; el cambio o mejora de la organización, con la optimización de los sistemas de producción, control de calidad, expansión institucional; los problemas de rendimiento, es decir, la falta de cumplimiento de los objetivos de la organización que repercute en el desarrollo de la tarea y en la consecución de los índices de productividad considerados como imprescindibles para la organización; la motivación, el absentismo laboral, la política de recompensas y de promoción; la realidad laboral o las transformaciones del mercado de trabajo (política de contratación, nueva legislación, etc.).

En definitiva, las necesidades de formación pueden vincularse directamente a decisiones de estrategia organizativa, pueden ser fruto del análisis de los resultados (rentabilidad, conflictividad, deserción, etc.), o pueden derivarse de problemas individuales de índole competencial.

\subsubsection{Los criterios de prioridad básicos}

Una vez recorrido el camino precedente, hay que proceder a realizar la última operación antes de dar paso al diseño específico del programa de formación: la priorización de las necesidades. Dado que las necesidades de formación en una organización suelen ser muchas y que los recursos disponibles son limitados, es necesario priorizar las primeras para determinar a cuáles es fundamental dar respuesta. Esta priorización se basa en unos criterios que varían en función de cada organización, existiendo sin embargo unos de carácter básico, comunes a todas ellas, que serían (Pineda, 1995, 38): relación coste-eficiencia de las necesidades formativas detectadas (inversión necesaria en función de los recursos disponibles y adecuación al marco presupuestario de la organización), requisitos y obligaciones legales, exigencias de los órganos directivos, colectivo por atender (tamaño y repercusiones o sinergias en la organización) y recursos disponibles.

La priorización de necesidades es, por tanto, el último paso en la determinación de necesidades formativas, pero ello no le resta importancia, ya que su omisión o su realización incorrecta puede conducir a un derroche de esfuerzos y al fracaso de la función formativa. 


\subsection{Fases de elaboración}

En este momento entramos en una etapa muy importante: la elaboración del programa de formación, que se concibe como una manera de mejorar el aprovechamiento de recursos, facilitar sinergias y disponer de una visión global, organizada y con criterios bien definidos.

La programación de la formación parte, por tanto, del conocimiento previo de la realidad (evaluación del contexto y detección de necesidades), para así organizar el conjunto de elementos que intervienen en cualquier programa educativo (objetivos, contenidos, estrategia formativa, metodología, técnicas, gestores de la formación, organización, duración, presupuesto, recursos, implementación, evaluación y auditoría), de acuerdo a los principios de formación establecidos organizativamente y a las circunstancias y posibilidades con que tal formación deberá aplicarse (Méndez, 2002). Se trata, evidentemente, de una tarea técnica, puesto que la determinación de los elementos indicados, así como sus mutuas relaciones, debe llevarse a cabo conforme a criterios justificados según los conocimientos que hoy existen en materia de desarrollo de recursos humanos (Colom, Sarramona y Vázquez, 1994, 67). Una tarea que, sin embargo, no debe concebirse linealmente, sino más bien cíclicamente, pues el diseño de cada una de sus fases encuentra su origen en la anterior y es el detonante de la siguiente, y el buen o mal planteamiento de cada una de ellas revierte en el buen o mal funcionamiento de todo el sistema diseñado.

\subsubsection{Diagnóstico de los destinatarios}

En palabras de Tres Viladomat (2002, 93-94), el diagnóstico de los destinatarios de la acción formativa y sus características es un proceso crucial para el buen desarrollo del proceso global de diseño de un programa de formación. Parece difícil poder acertar en las decisiones que deben tomarse en el diseño sin conocer con exactitud las peculiaridades de quienes van a ser los participantes directos en la formación.

La información que debe obtener el diseñador sobre los destinatarios se resume en siete grandes áreas:

- Información personal.

- Experiencia profesional y proyección.

- Necesidad formativa.

- Conocimientos sobre la materia.

- Motivación y predisposición al estudio.

- Referencias y predisposición hacia ciertas modalidades y metodologías.

- Objetivos personales.

Aunque parezca reiterativo realizar un estudio pormenorizado de los destinatarios tras un exhaustivo análisis de necesidades, resulta imprescindible no 
olvidarlo en aras de contextualizar cada programa de formación de manera diferenciada. Nos apoyamos para efectuarlo en las mismas herramientas que empleamos para la precedente detección de las necesidades, pero recabamos ahora información complementaria, más útil para la selección de los objetivos, contenidos y estrategias de formación de los participantes.

\subsubsection{Formulación de objetivos}

El propósito al marcarse objetivos en formación es establecer desde un principio las expectativas de los formandos sobre su preparación al finalizar la actividad formativa (o al final de cada etapa), sobre las condiciones en que tendrán que demostrar lo aprendido y los niveles que tienen que alcanzar para ser competentes. Unos objetivos redactados con toda claridad sirven como medio para evaluar y dar validez a la formación, así como para ayudar al formador a elegir el método y los contenidos del programa.

Un objetivo se puede definir como el resultado que se espera de los sujetos en formación al finalizar ésta. En función de esta conducta deseada se planteará todo el diseño (Pineda, 1995, 38-39).

Desde este punto de vista, un factor clave en la formulación de los objetivos es la integración en esta fase del personal implicado, comunicándole la finalidad del programa de formación y despertando su interés en virtud de las posibilidades, beneficios y alternativas laborales que tal formación le va a reportar.

A este respecto, en cualquier trabajo de diseño de la formación consideramos importante distinguir, siguiendo a Le Boterf $(1991,141)$ : el campo que abarcan los objetivos (se establecerán los objetivos globales o terminales y los objetivos específicos o intermedios) y el tipo de uso que se piensa hacer de esos objetivos (se precisarán los objetivos de formación y los objetivos pedagógicos).

Los objetivos globales expresan, de manera sintética, el comportamiento profesional global que debe alcanzarse al finalizar la formación y que ha de ponerse en práctica en una situación de trabajo. Son los que se vinculan con objetivos de recuerdo, resolución de problemas, aplicación de normas, consolidación de compromisos personales. Son los objetivos que se establecen desde la dirección. Los objetivos específicos explican el conjunto de conocimientos, habilidades o actitudes (competencias) que es preciso adquirir para alcanzar el objetivo final. Son los objetivos que pretenden la participación de los destinatarios de la formación en los debates organizados, la aceptación de las orientaciones dadas por el formador, el cumplimiento de las normas que rigen los programas formativos (horarios, plazos...). Son los objetivos que plantea el coordinador de la formación.

Los objetivos de formación se formulan para identificar el resultado que se espera de la actuación formativa. Sirven para centrar los programas de formación, 
pero no son lo bastante precisos para orientar las estrategias pedagógicas. Son los objetivos que aparecen en los diferentes bloques temáticos del programa. Los objetivos pedagógicos sirven a los formadores para preparar, llevar a cabo y evaluar sus sesiones formativas. Se caracterizan, pues, por una mayor exigencia en su formulación y están destinados a concretar, a hacer operativos los objetivos de formación. Implican un conocimiento de los contenidos que se deben adquirir, de sus dificultades, de las estrategias pedagógicas que hay que poner en práctica. Expresan más lo que los formandos deben aprender que lo que deben hacer en las situaciones reales de trabajo. Son los objetivos que se concretan en cada sesión de formación.

Una formulación en términos de objetivos de formación debe cumplir cinco condiciones: enunciar lo que el alumno debe "ser capaz de" realizar al término de la formación mediante verbos que expresen acciones observables (construir, conducir, experimentar...), elegir el verbo de acción de manera que permita evidenciar el nivel de objetivo al que se quiere llegar (información, dominio de un lenguaje, dominio de una herramienta, cambio actitudinal...), expresar esta acción principal desde el punto de vista del sujeto que aprende (el alumno deberá ser capaz de...), evitar calificativos imprecisos tales como minimiza, maximiza, mejora, etc., y formular el objetivo en términos de resultados y no en términos de proceso de aprendizaje. Por su parte, una formulación en términos de objetivos pedagógicos debe satisfacer dos condiciones específicas además de las cinco que acabamos de enunciar: precisar las condiciones en las que la acción principal debe realizarse (tipo de información y aparatos disponibles, dificultades de experimentación...) e indicar las normas o niveles de rendimiento (tiempo limitado en el que se desarrolla la prueba, mínimo de respuestas justas, porcentaje de éxitos o de errores...).

No obstante, ya nos refiramos a objetivos de formación o a objetivos pedagógicos, globales o específicos, en función de las necesidades descubiertas y de las competencias a las que se encuentren asociadas, estaremos hablando de:

- Objetivos del ámbito de los conocimientos ("Saber").

- Objetivos del ámbito de las habilidades ("saber hacer").

- Objetivos del ámbito de las actitudes ("saber ser" y "Saber estar").

Cada uno de estos ámbitos puede estructurarse en diversos niveles de dificultad: de interiorización, integración personal o innovación, en el caso de los objetivos de conocimiento; puntuales o procesuales, en el caso de los relativos a habilidades, y de referencia personal o social, en el caso de los actitudinales (Colom, Sarramona y Vázquez, 1994, 71).

Esta estructura divisional debe permitirnos constatar la consecución de los objetivos. Los criterios que proponemos con tal objeto, junto con los autores precedentes, son: relevancia, esto es, que los objetivos que se pretende conseguir merezcan los esfuerzos que se invertirán en su logro; claridad de formulación, que tiene que ver con la directa vinculación con uno de los ámbitos indicados y con la 
concepción clara en la mente del formador; contextualización, estableciendo conexiones entre los objetivos y las experiencias concretas en el puesto de trabajo; posibilidad de evaluación, en un sentido amplio, no sólo como control final de resultados.

\subsubsection{Elección y organización de los contenidos}

El establecimiento de los contenidos de formación es la siguiente fase en el proceso de programación. Los contenidos de la formación en la organización pueden ser muy variados, en función de las necesidades formativas y de los objetivos derivados de ellas a que dan respuesta. Sin embargo, se pueden identificar tres campos generales de acción de la formación en relación con los contenidos (Pineda, 1995, 41):

1. Conocimiento de la propia organización: Son los contenidos referidos al conocimiento de la filosofía, la estructura, el sistema, la imagen, etc., de la organización.

2. Conocimientos profesionales: Son los contenidos que proporcionan los conocimientos competenciales necesarios para realizar las tareas que integran cada puesto de trabajo.

3. Formación personal: Incluye todos los conocimientos que están más allá de las competencias profesionales y que permiten considerar a la persona como miembro de una comunidad laboral y social, contemplándola así como una totalidad desde un enfoque integral que hace que la formación en la organización no sea sólo de tipo profesional, sino también educativa y altamente enriquecedora para el individuo ${ }^{3}$.

Por otra parte y, para ser congruentes con la tipología de objetivos identificados previamente, podemos encontrar contenidos vinculados al saber, al saber hacer y a las actitudes. Unas simples aclaraciones bastarán para identificar estos grupos de contenidos (Colom, Sarramona y Vázquez, 1994, 75-76):

- Los contenidos vinculados al saber serían: Objetos y hechos (realidades concretas), conceptos e ideas (abstracciones a partir de los precedentes), principios y leyes (conjunto organizado de conceptos).

- Los contenidos vinculados al saber hacer serían: Normas de acción (directrices puntuales de cómo se debe ejecutar una acción mental o manual), técnicas (acciones encadenadas que resuelven situaciones más complejas con eficacia) y criterios (elementos para la toma de decisiones).

3. En este caso nos estamos refiriendo a las denominadas "competencias transversales", las cuales podemos considerarlas como aquellas competencias genéricas, comunes a la mayoría de las profesiones y que se relacionan con la puesta en práctica de manera integrada de las aptitudes, rasgos de personalidad, conocimientos adquiridos y también valores. 
- Los contenidos vinculados a las actitudes serían: Valores personales (autonomía, iniciativa, creatividad, responsabilidad) y sociales (colaboración, solidaridad, espíritu de equipo...).

Independientemente del tipo de contenidos de que se trate, el proceso de selección y de elaboración de los mismos en un programa de formación ha de atender a los siguientes criterios: a los objetivos fijados, a las características del colectivo destinatario, a la modalidad formativa elegida, al tiempo disponible, a la situación y al entorno laboral y a las condiciones espacio-temporales (contextualización). Estos elementos determinarán los contenidos seleccionados como integrantes del programa de formación. Pero la selección de los contenidos no es suficiente, es necesario organizarlos y estructurarlos en función de los principios pedagógicos que garantizan la eficacia y la eficiencia de la formación. Esos principios son:

a) Aligeramiento de contenidos con dificultad variable.

b) Interdisciplinariedad (integración de ámbitos diversos pero relacionados).

c) Elaboración de mapas conceptuales para dotar de significatividad a los contenidos ${ }^{4}$.

d) Organización jerárquica de contenidos en: fundamentales (lo que hay que saber), complementarios (lo que se debería saber) y anécdotas, ejemplos o ampliaciones (lo que se podría saber), utilizando para ello cuadros sinópticos y teniendo siempre presente la unidad de contenidos de la acción formativa.

e) Secuencia lógica de contenidos (por medio de diagramas de flujo que representan de forma gráfica las fases de un proceso, la secuencia de pasos a seguir y sus interrelaciones).

La identificación, selección y organización de los contenidos de un programa de formación debe apoyarse, finalmente, en las pautas normativas vigentes en nuestro país ${ }^{5}$, que recogen como necesario:

- La estructura modular de los contenidos, que permita su concreción en unidades de competencia.

4. Es la representación esquemática y jerárquica del conjunto de significados conceptuales incluidos en una estructura de proposiciones y sus relaciones. En último término, se trata de encontrar y mostrar relaciones entre los conceptos contenidos en un texto (SÁNCHEZ CEREZO, 1991, 332-333).

5. Actualmente, y en virtud del II Programa Nacional de Formación Profesional (19982002), se crea el INCUAL - Instituto Nacional de las Cualificaciones Profesionales- (1999), cuya misión fundamental consiste en «el diseño de un sistema integrado de cualificación y formación profesional", con el que se quiere dar respuesta a la necesidad de establecer los niveles de extensión y características de la competencia profesional que debe ser alcanzada en los campos de la actividad productiva. Hoy se encuentra respaldado por la Ley Orgánica 5/2002 de las Cualificaciones y de la Formación Profesional (BOE, 20 de junio de 2002). 
CAROLINA FERNÁNDEZ-SALINERO MIGUEL

UN ENFOQUE PEDAGÓGICO PARA EL DISEÑO DE PROGRAMAS DE FORMACIÓN EN CONTEXTOS ORGANIZATIVOS

- Su integración en los contenidos del perfil profesional de referencia, en orden a conseguir el certificado de profesionalidad correspondiente.

- La búsqueda de la normalización de la competencia común en pos de la calidad de la formación.

\subsubsection{Selección de la estrategia de formación}

Una de las decisiones más importantes en el proceso de diseño de programas formativos es la selección de la estrategia de formación que va a facilitar la consecución de los objetivos. Pero, ¿qué se entiende por estrategia formativa? Una respuesta clara es la que aporta Tres Viladomat $(2002,101)$ y que a nosotros nos parece acertada: la estrategia de formación se debe entender como la combinación de una modalidad, una metodología, una técnica y un soporte.

La modalidad formativa viene definida por las condiciones en las que se desenvuelve el programa de formación. Así, pueden considerarse como modalidades aquellas que surgen de las dicotomías entre: formación en el puesto de trabajo/formación fuera del puesto de trabajo; autoformación/formación en grupo; formación presencial/formación administrada a distancia.

La metodología es la manera de organizar los recursos y presentar el contenido para llegar a alcanzar los objetivos. Las metodologías pueden ser activas, demostrativas o expositivas.

Las técnicas son planteamientos que nos indican cómo llevar a la práctica las metodologías y están definidas por normas de implementación y aplicación directa. Existe un gran número de técnicas de formación, las más destacadas son: lección magistral, conferencia, demostración, seminario, taller, role-playing, estudio de casos, juegos de empresa, mentoring, coaching, y un emergente número de nuevas técnicas de formación en el puesto de trabajo como el aprendizaje en acción, el aprendizaje a partir de procesos o el aprendizaje a través de la resolución de problemas en equipos multidisciplinares.

El recurso tecnológico es el último elemento de la estrategia. Se trata del soporte o medio con el que transmitimos el contenido del programa de formación. En este sentido, el papel, el audio, el vídeo, el ordenador (con todas sus variantes: CD-ROM o vía Internet) son ejemplos de los recursos más comunes.

Pero para seleccionar la estrategia formativa más adecuada deben tenerse en cuenta tres criterios básicos: el tipo de objetivos (conocimiento, habilidades o actitudes), las características del público destinatario (número de participantes, nivel de partida, predisposición hacia ciertas técnicas) y las limitaciones de los recursos (económicas, tecnológicas, temporales). Partiendo de estos presupuestos pasamos a continuación a precisar un poco más detalladamente los elementos que conforman la estrategia de formación. 


\subsubsection{Identificación de la modalidad de formación}

La formación en las organizaciones se conforma como un instrumento de mejora y optimización de las potencialidades de los trabajadores, tanto de manera individual como colectiva, y tanto desde una perspectiva de respuesta (reactiva) como de anticipación (proactiva). Las modalidades para su desarrollo deben ser, por tanto, diferentes y adecuadas a cada una de las peculiaridades que adopte la misma. Sin olvidar la existencia de unos planteamientos básicos que han de tenerse en cuenta:

- La formación busca conocer cosas que ayuden a las personas en su actividad laboral.

- La formación ha de experimentar los conceptos precedentes para verificar su utilidad.

- La formación necesita vivir los cambios que se operen en el lugar de trabajo derivados de lo que hemos aprendido y de cómo lo estamos poniendo en práctica.

Estos tres puntos nos permiten identificar la estructura fundamental de las modalidades señaladas, las cuales pueden asumir también tres formas de desarrollo.

En primer lugar, incidiríamos en todas aquellas maneras de actuar que se sustentan en la voz como vehículo de la formación (hable). La modalidad presencial se apoya en la transmisión oral de la información a través de la figura del formador como protagonista del proceso de aprendizaje. El saber es su objetivo fundamental, aunque cada vez más esté orientando sus planteamientos a la aplicación. En segundo lugar hariamos referencia a la experimentación como herramienta formativa (demuestre). La modalidad a distancia requiere la participación activa del alumno en el proceso formativo, su implicación en la generación del conocimiento y la interacción con los diferentes sistemas de autoformación que se pongan a su alcance. El saber hacer es su meta más fuerte, de manera especial en el momento presente donde el e-learning (aprendizaje electrónico) o la formación on line se perfilan como nuevas vías de autoaprendizaje. Y, en tercer lugar, hablaríamos de la acción directa y responsable de los participantes como mecanismo formativo (actúe). La modalidad de formación in situ se define concretamente como aquella que utiliza el lugar de trabajo como fuente de aprendizaje, desarrollándose la cualificación en un entorno real. En este caso el saber vivir es el exponente de la formación, pues es el feedback constante de la actuación formativa lo que se aprende, valora y asimila.

Con todo ello, descubrimos que la tipología de los aprendizajes determina la modalidad de formación más adecuada y que no existe una modalidad que favorezca la adquisición de un único tipo de saber, ni un saber que se pueda conseguir solamente por una modalidad. La combinación de aprendizajes y la complementariedad de las modalidades ha de ser el objetivo real de una buena y fructífera formación. 
Otros dos criterios básicos nos permiten hablar de diversas modalidades formativas, éstos son: el agente y el lugar de impartición de la formación. Siguiendo estos criterios se pueden establecer tres grandes tipologías (adaptación de Pineda, 1995, 43-44):

- Formación interna: Se refiere a todos aquellos programas formativos que tienen lugar dentro de la organización. Puede desarrollarse de dos maneras diferentes.

1) Formación en el puesto de trabajo: Que es la modalidad más común y más antigua, su forma más simple es la del aprendizaje por observación, aunque su realización más efectiva requiere un mayor rigor en la planificación y un enfoque formativo más sistemático. Nos referimos a una formación reactiva o que responde a una necesidad de competencia inmediata.

2) Formación fuera del puesto de trabajo: Que consiste en la actividad formativa desarrollada a través de cursos — largos y cortos-, seminarios, conferencias, encuentros, etc., a realizar dentro de la organización (de manera presencial o a distancia, dentro o fuera del horario laboral). Dichos programas pueden ser de adaptación al puesto, de reciclaje, de promoción (tres tipos de formación reactiva), de perfeccionamiento o de desarrollo de la competencia (dos tipos de formación proactiva o anticipadora al cambio), si seguimos la clasificación de paradigmas de formación establecida por Castillejo et al. (1988, 427).

- Formación externa: Hace referencia a todas aquellas actividades formativas organizadas por agentes externos y llevadas a cabo fuera de la organización. Existe una gran oferta de programas formativos externos y una variada gama de posibilidades de elección que se adecua a todas las necesidades y exigencias (ya sean reactivas o proactivas). Las organizaciones suelen utilizar la formación externa cuando no disponen de infraestructura y recursos necesarios para ponerla en marcha por sí mismas, o cuando se considera más adecuado para la efectividad del aprendizaje el enviar a los participantes a formarse fuera. Pero hay que ser cauteloso, pues este tipo de formación si no se hace a la medida de las necesidades del cliente se convierte en una trampa, al no proporcionar más que actividades de formación estándar de escasa validez laboral.

- Formación combinada: Permite desarrollar, según necesidades e intereses, las dos alternativas anteriores, procurando conseguir una estructura sistemática e integrada de modalidades de formación, más adaptada a la realidad empresarial actual y más acorde con las posibilidades formativas y tecnológicas de la sociedad de la información y el conocimiento. 
Contemplaría actuaciones reactivas y proactivas complementarias y dentro de una estrategia coherente de desarrollo.

La selección de una u otra modalidad formativa va a venir motivada por los objetivos perseguidos, por los recursos disponibles, por la adecuación de los aprendizajes a las necesidades del negocio, por los costes que conlleva cada opción o por la oferta de formación consultada

\subsubsection{Selección de las estrategias metodológicas y sus técnicas}

El método, como su propia etimología indica ${ }^{6}$, nos informa sobre el camino a seguir. Por lo que actuar metódicamente implicará actuar de acuerdo a un orden o procedimiento. Si seguimos a Colom, Sarramona y Vázquez $(1994,82)$, los métodos o estrategias metodológicas dentro de la planificación de la formación se constituyen, por lo tanto, en el conjunto de situaciones y actuaciones que los formadores prepararán y llevarán a cabo durante el proceso de formación para conseguir que los destinatarios de tal formación alcancen los conocimientos, habilidades y actitudes previstas (competencias profesionales).

Las técnicas, en este sentido, nos concretan diferentes formulaciones en relación con un mismo método. Pero, cuando hablamos de técnicas, nos referimos al recurso didáctico al cual se acude para concretar un momento de la formación o una secuencia del método en la realización del aprendizaje. Es decir, el método seleccionado para alcanzar los objetivos debe concretarse en una serie de técnicas. Al mismo tiempo, el método nos va a llevar a reflexionar sobre qué técnicas nos van a conducir mejor al logro de los objetivos y se van a adecuar mejor a las características de los participantes. Esto es, cuáles les van a atraer más y a la vez van a respetar su propio ritmo de aprendizaje.

Resulta conveniente, a este respecto, apoyarse en diferentes métodos y técnicas y no en uno/a únicamente. Por esta razón, la preparación y conducción de las actividades de un programa de formación requiere del formador:

- Actitud ecléctica para asumir el principio de multivariedad metódica.

- Capacidad para improvisar cambios, lo que implica una actitud reflexiva, crítica, abierta e innovadora sobre su trabajo.

- Adaptabilidad al grupo con quien debe empatizar e interactuar.

Los métodos y técnicas dan forma a la puesta en escena. Nos indican cómo organizar las actividades o experiencias de aprendizaje que han de llevar a la

6. Según el Diccionario de las Ciencias de la Educación (Aula Santillana, 1988, 934), significa literalmente camino que se recorre. Por consiguiente, actuar con método se opone a todo hacer casual y desordenado. Actuar con método es lo mismo que ordenar los acontecimientos para alcanzar un objetivo. 
CAROLINA FERNÁNDEZ-SALINERO MIGUEL.

consecución de los objetivos; es decir, qué hacemos y cómo lo hacemos, tanto formadores como alumnos.

No obstante, la diversidad de situaciones formativas en las que podemos vernos involucrados nos permite hablar de una gran variedad de estrategias metodológicas en formación, tantas que para aproximarse al tema es necesario partir de alguna clasificación. Las clasificaciones existentes son distintas: hay autores como Castillejo, Sarramona y Vázquez (1988) que las clasifican en función del tipo de objetivo al que responden (cognitivo, psicomotriz y afectivo); otros autores como Goldstein (1986) clasifican los métodos en relación con las destrezas que potencian (conocimientos, habilidades sociales, interpersonales, etc.); algunos en función del grado de implicación de los participantes (De Ketele et al., 1988); otros autores en relación con el grado de control y de delegación del contenido por parte del formador (Pineda, 1995); algunos más en función del grado de participación del formador y del alumno en la dinámica del proceso de enseñanza y aprendizaje (Viladot, 2002); etc.

De todas ellas, sin dejar de lado ninguna de manera tajante, la que resulta más clara es la que toma como referente el grado de participación del formador y del alumno en la dinámica del proceso de enseñanza-aprendizaje.

Si nos apoyamos en estos criterios, podemos hablar de tres grandes grupos de estrategias metodológicas, cada uno de los cuales nos permite identificar unos métodos específicos, con sus técnicas ad hoc. La estructura metodológica a la que nos referimos se recoge en la tabla siguiente: 
CAROLINA FERNÁNDEZ-SALINERO MIGUEL

UN ENFOQUE PEDAGÓGICO PARA EL DISEÑO DE PROGRAMAS DE FORMACIÓN EN CONTEXTOS ORGANIZATIVOS

\begin{tabular}{|c|c|c|c|}
\hline & $\begin{array}{l}\text { ESTRATEGIA } \\
\text { METODOLÓGICA } \\
\text { EXPOSITIVA }\end{array}$ & $\begin{array}{c}\text { ESTRATEGIA } \\
\text { METODOLÓGICA } \\
\text { DEMOSTRATIVA }\end{array}$ & $\begin{array}{c}\text { ESTRATEGIA } \\
\text { METODOLÓGICA } \\
\text { ACTIVA }\end{array}$ \\
\hline CARACTERISTICAS & $\begin{array}{l}\text { Exposición oral } \\
\text { unidireccional, } \\
\text { presentación de } \\
\text { contenidos con base } \\
\text { académica, tratamiento } \\
\text { individual y colectivo, } \\
\text { feedback aplazado. }\end{array}$ & $\begin{array}{l}\text { Situación real de trabajo, } \\
\text { implicación de los } \\
\text { trabajadores, } \\
\text { conocimiento inicial de } \\
\text { la actividad laboral y } \\
\text { refuerzo de } \\
\text { conocimientos previos, } \\
\text { tratamiento individual y } \\
\text { colectivo, feedback } \\
\text { inmediato. }\end{array}$ & $\begin{array}{l}\text { Representación } \\
\text { manipulable de la } \\
\text { realidad para la toma de } \\
\text { decisiones y la } \\
\text { resolución de problemas, } \\
\text { conocimiento anticipatorio, } \\
\text { creatividad y respuesta } \\
\text { activa, aprendizaje } \\
\text { vivencial, tratamiento } \\
\text { individual y colectivo, } \\
\text { feedback a corto plazo. }\end{array}$ \\
\hline $\begin{array}{l}\text { MÉTODOS } \\
\text { ESPECÍFICOS }\end{array}$ & $\begin{array}{l}\text { Exposición oral. } \\
\text { Autoformación. }\end{array}$ & $\begin{array}{l}\text { Formación tutorizada. } \\
\text { Formación «in situ». } \\
\text { Círculos de calidad. }\end{array}$ & $\begin{array}{l}\text { Simulación. } \\
\text { Outdoortraining. } \\
\text { Formación-acción. }\end{array}$ \\
\hline TÉCNICAS & $\begin{array}{l}\text { Lección magistral, } \\
\text { conferencia, simposio, } \\
\text { charla, mesa redonda, } \\
\text { teleconferencia/ } \\
\text { videoconferencia, } \\
\text { programas seriados, } \\
\text { preguntas exploratorias, } \\
\text { Bencbmarking (análisis } \\
\text { de buenas prácticas). }\end{array}$ & $\begin{array}{l}\text { Training Witbing } \\
\text { Industry (adiestramiento } \\
\text { en técnicas manuales), } \\
\text { Roting (rotación por } \\
\text { diferentes puestos), } \\
\text { Coaching (formación } \\
\text { tutorizada por un } \\
\text { experto), Mentoring } \\
\text { (formación a través del } \\
\text { modelado). }\end{array}$ & $\begin{array}{l}\text { Estudio de casos, } \\
\text { bandeja de } \\
\text { correspondencia, } \\
\text { proceso de incidente } \\
\text { crítico, role-playing, } \\
\text { juegos de empresa, } \\
\text { trabajo en equipo, } \\
\text { Phillips 66, lluvia de } \\
\text { ideas. }\end{array}$ \\
\hline OBJETIVOS & \begin{tabular}{|l} 
Conocimiento y \\
actitudes. \\
\end{tabular} & $\begin{array}{l}\text { Conocimientos y } \\
\text { habilidades. }\end{array}$ & Habilidades y actitudes. \\
\hline $\begin{array}{l}\text { PERFIL DEL } \\
\text { FORMADOR }\end{array}$ & Profesor, instructor, tutor. & $\begin{array}{l}\text { Orientador, supervisor, } \\
\text { demostrador. }\end{array}$ & $\begin{array}{l}\text { Animador, facilitador y } \\
\text { motivador. }\end{array}$ \\
\hline $\begin{array}{l}\text { PUNTOS } \\
\text { FUERTES }\end{array}$ & $\begin{array}{l}\text { Estructuración del } \\
\text { contenido rápida y } \\
\text { generalizada, transmisión } \\
\text { de información. }\end{array}$ & $\begin{array}{l}\text { No requiere infraestructura, } \\
\text { promueve la participación } \\
\text { del trabajador, motivación, } \\
\text { conocimiento real del } \\
\text { lugar de trabajo, } \\
\text { seguimiento continuo de } \\
\text { la acción. }\end{array}$ & $\begin{array}{l}\text { Proceso transferible, } \\
\text { relación reflexión teórica } \\
\text { con experiencia práctica, } \\
\text { motivación, aprendizaje } \\
\text { personalizado, } \\
\text { alternancia, polivalencia, } \\
\text { respuesta real. }\end{array}$ \\
\hline PUNTOS DÉBILES & $\begin{array}{l}\text { Caída de la atención, } \\
\text { pasividad del } \\
\text { participante, autocontrol } \\
\text { del participante. }\end{array}$ & $\begin{array}{l}\text { Excesiva especialización } \\
\text { del formador, práctica } \\
\text { compleja, aprendizaje } \\
\text { especializado, alto coste } \\
\text { económico y de recursos } \\
\text { humanos. }\end{array}$ & $\begin{array}{l}\text { Dificultad para seleccionar } \\
\text { representaciones } \\
\text { adecuadas y transferir } \\
\text { resultados, inversión } \\
\text { necesaria en tiempo y } \\
\text { dinero, evaluación poco } \\
\text { rigurosa de los resultados. }\end{array}$ \\
\hline
\end{tabular}

Elaboración propia. 
CAROLINA FERNÁNDEZ-SALINERO MIGUEL

UN ENFOQUE PEDAGÓGICO PARA EL DISEÑO DE PROGRAMAS DE FORMACIÓN EN CONTEXTOS ORGANIZATIVOS

La tipología establecida nos permite hablar de numerosas y muy variadas metodologías útiles en función de la orientación formativa hacia el conocimiento, las habilidades o las actitudes. De esta abundante clasificación parece interesante destacar como las más sobresalientes y empleadas en el mundo organizativo, las que en la tabla precedente se señalan.

\subsubsection{Recursos necesarios}

Son recursos para la formación cualquier medio, persona, material, procedimiento, etc., que con una finalidad de apoyo se incorpora en el proceso de aprendizaje, para que cada alumno alcance el limite superior de sus capacidades, potenciando así su aprendizaje (Sánchez Cerezo, 1991, 453).

Para la correcta utilización de los recursos así definidos existen dos aspectos que cualquier formador debe saber y tener en cuenta: algunos recursos sirven más que otros para transmitir ciertos mensajes y los recursos influyen, significan y modifican los contenidos que transmiten. De estas dos premisas se desprende el hecho de que el responsable de la formación debe conocer las características y la incidencia de los recursos, a fin de que pueda elegirlos y utilizarlos de acuerdo con los objetivos que previamente se hubiese planteado. Así pues, el formador respecto a los medios debe poseer el conocimiento previo de sus efectos y funciones, el conocimiento de su manejo y la capacidad de aplicarlos en situaciones reales (Colom, Sarramona y Vázquez, 1994, 87-88). Existen dos grandes grupos de recursos:

- Recursos bumanos. Son los sujetos implicados como agentes del proceso formativo: expertos, técnicos pedagógicos, coordinadores, profesorado y personal de apoyo de la función formativa. Los tres primeros van a ser objeto de epígrafes posteriores, con respecto al último, identificarlo como aquel conjunto de personas que desarrollan tareas que, a pesar de no estar directamente relacionadas con la formación, sirven de base y posibilitan la implementación de la misma (secretariado, personal de limpieza, personal de mantenimiento, equipo de apoyo informático-tecnológico, etc.). A éstos se unen los sujetos participantes (usuarios o clientes).

- Recursos materiales. La gran diversidad de materiales utilizados para la formación puede agruparse en dos grandes bloques: instalaciones (estructuras físicas donde tiene lugar la formación) y materiales pedagógicos (textos impresos didácticamente preparados, recursos audiovisuales, informáticos y multimedia). 


\subsubsection{Gestión de los programas}

Tal como se desprende de la lectura de los apartados precedentes, diseñar un programa formativo es un tipo de proyecto que requiere una aproximación profesional. En todo el proceso descrito aparecen diversas funciones que pueden recaer fácil y convenientemente en personas diferentes que deben ser coordinadas por alguien. Por ello, se recomienda una gestión del programa, tratándolo como un proyecto formativo.

\subsubsection{Identificación de las figuras básicas de un programa de formación}

Los diferentes profesionales requeridos para la actividad formativa en la organización se pueden clasificar en los siguientes grupos:

- El director de formación, quien establece o recoge las líneas estratégicas que en materia formativa se reconocen como fundamentales dentro de la compañía.

- El programador, que elabora las especificaciones de diseño y los materiales escritos.

- Los expertos, que pueden aportar documentación y/o validar el producto desde distintos puntos de vista (técnico, pedagógico, etc.).

- El coordinador de producción, responsable de la edición y la distribución del producto.

- El formador, instructor o tutor, es decir, la persona que se relaciona con el destinatario.

Cada uno de ellos debe desempeñar su papel convenientemente, aunque, en algunas ocasiones, una misma persona puede asumir varias funciones (por ejemplo, un experto en pedagogía puede ser luego el formador del curso que se ha diseñado).

\subsubsection{Organización de las sesiones}

En relación con la organización de la actividad formativa nos vamos a referir a los siguientes elementos: las condiciones ambientales, el lugar de desarrollo, los horarios y tiempos empleados y la programación de las sesiones.

1. Las condiciones ambientales. La formación debe llevarse a cabo en lugares caracterizados por la comodidad, facilidad de acceso para todos (incluidos los minusválidos), limpieza del lugar, movilidad (posibilidad de cambio en la distribución de los muebles), ambiente grato (nivel de ruidos controlado), espacio suficiente, luminosidad y climatización. 
2. El lugar. Depende de los objetivos que se persigan y de los recursos disponibles. Tres son las posibilidades más utilizadas en la actualidad: en la propia organización (no hay desplazamientos y sí mayor transferencia, aunque suele haber interrupciones y pocos medios pedagógicos), en residencia (desconexión del trabajo habitual e incremento de cohesión de grupo, aunque resulta costoso y exige formación en régimen continuo), en un centro de formación (locales bien adaptados pedagógicamente y clima de estudio, aunque impresión de "escuela" y adaptación a las exigencias del establecimiento y no del grupo).

3. Los horarios. La elección del horario en que se impartirán las clases no es una cuestión trivial. Lo primero que hay que hacer es elegir entre impartir la formación dentro del horario de trabajo o fuera de él. El horario dentro de la jornada laboral requiere poder prescindir de los asistentes en el puesto de trabajo y el horario fuera de la jornada laboral requiere motivación suficiente por parte de los participantes. El horario tiene también condicionantes pedagógicos: normalmente el rendimiento de alumnos y profesores es superior por la mañana que por la tarde, y el principio y fin de la semana no son días aconsejables para realizar la formación, los días centrales son los más provechosos. Tiene además condicionantes técnicos (turnos de trabajo, coincidencia con los momentos de máxima actividad de la organización, superposición de distintos programas dirigidos a las mismas personas).

4. Los tiempos. En relación con este punto podemos distinguir entre (Grappin, 1990, 29-30): "tiempos globales" que dependen de los objetivos, los participantes (nivel, heterogeneidad, efectivos), lo ambicioso o limitado del programa, los formadores, los recursos... Y “tiempos secuenciales" o división de los tiempos globales. La unidad de tiempo secuencial es la media jornada (tres horas, tres horas y media o cuatro horas), a condición de que se alternen los objetivos, los métodos y los medios pedagógicos, previendo y respetando una o dos pausas de veinte minutos cada una. Las sesiones de media jornada son mas útiles para formación inicial, y de jornada completa (de seis a ocho horas) para formación continua. La secuencia de las sesiones debe hacerse en orden a la estructura del programa; intercalando sesiones más distendidas entre otras más complejas, siempre que se respete el equilibrio pedagógico del programa formativo.

\subsubsection{Duración del programa de formación}

La duración del programa dependerá del tipo de actividad formativa que pretendamos realizar.

A continuación vamos a aproximarnos a una posible categorización con su duración correspondiente: 
1. Adaptación al puesto (formación colectiva presencial o a distancia): seminarios nocturnos, cursillos de dos a cuatro días, estancias, encuentros o reuniones informativas, autoformación. Corta duración (hasta 40 horas).

2. Desarrollo de la competencia (formación individual y colectiva): programas basados en proyectos, equipos de trabajo intraorganizativo, grupos de intercambio de experiencias. Duración media (de 41 a 100 horas) o. larga (más de 100 horas).

3. Formación individual (perfeccionamiento y promoción): autoformación, educación a distancia o sistemas de enseñanza interactiva asistida por ordenador. Duración variable.

4. Formación continua (reciclaje): programas estructurados de desarrollo organizativo, seminarios, cursillos de formación organizativa, programas in-company (adaptados a las necesidades específicas de la empresa). Duración variable.

\subsubsection{Precisión del presupuesto}

El proyecto económico que soporta un programa de formación puede estar vinculado al presupuesto de un ámbito de mayor tamaño (por ejemplo, recursos humanos, del cual formación será una de sus funciones), o bien constituirse en presupuesto diferenciado sin relaciones con otros (presupuesto de formación). Pueden existir situaciones diferentes e incluso mixtas: por ejemplo, que los distintos programas sectoriales de la compañia tengan apartados con recursos financieros para actividades de formación (seguridad e higiene en el trabajo, programas de calidad...), o también que cada división o área de línea tenga un presupuesto dirigido a costear sus propios programas. Naturalmente, cada una de estas operativas presupuestarias es consecuencia de un modelo de gestión formativa determinado (más o menos descentralizado) y su eficacia dependerá del acierto de sus decisiones y de su hacer (Gan et al., 1995, 151). Pero, independientemente del modelo de gestión formativa al que nos refiramos, el presupuesto debe recoger:

- Costes directos, asociados al coste de programas concretos. Ej.: compra externa de programas, salario de formadores y consultores externos, horarios de formadores internos, desplazamientos, dietas, documentos, alquiler de equipos e instalaciones...

- Costes indirectos: actividades dentro del horario laboral, gastos administrativos...

- Costes fijos o estructuras de formación: relativos a personal del departamento e infraestructuras y mantenimiento de las mismas.

- Costes variables, los no fijos derivados de la implementación de los programas (inesperada adquisición de recursos didácticos, fotocopias imprevistas de documentos, etc.). 
CAROLINA FERNÁNDEZ-SALINERO MIGUEL

UN ENFOQUE PEDAGÓGICO PARA EL DISEÑO DE PROGRAMAS DE FORMACIÓN

EN CONTEXTOS ORGANIZATIVOS

- Coste por programa de formación: número de días/horas de formación por empleado, número de participantes, duración media de la actividad, etc.

- Costes de programas por especialidad o área formativa (informática, comercial...).

- Costes de programas por departamento o área de trabajo (Marketing, Ventas...).

- Costes de programas por nivel jerárquico (directivos, mandos, técnicos, auxiliares...).

Pero, para calcular los costes de un proyecto de formación es necesario proceder a una localización sistemática de los costes correspondientes a las diferentes etapas de concepción, realización, seguimiento y evaluación de ese proyecto. En la práctica se debe comenzar por establecer un listado completo de las operaciones, para luego poder asignarles un coste. El total de estos costes por separado dará el coste global del proyecto (Le Boterf, 1991, 188).

A partir de este conjunto de estimaciones es posible hacer un seguimiento diferenciado del presupuesto, relacionándolo con los distintos colectivos y áreas de trabajo implicadas, e identificando la cuantía y clase de recursos asignados a cada ámbito. La finalidad de estos análisis es buscar el equilibrio entre tres variables: calidad-tiempo-coste. Las tres forman un imaginario triángulo cuyos lados deben ser iguales. La situación ideal es que exista una proporcionalidad entre los tres factores, de este modo se obtendrá una solución eficiente.

\subsection{Lineas de ejecución}

Las etapas planteadas hasta ahora culminan en la fase donde hay que transferir a las personas seleccionadas los aprendizajes programados según la temporalización prevista. Es un momento donde concurren, para los responsables de formación, las tareas de información, coordinación y seguimiento de los programas formativos que se irán llevando a cabo; siendo básico conjugar múltiples elementos y variables (participantes, coordinadores, formadores internos o externos, mandos de los participantes, infraestructuras, recursos materiales, horarios, actividades, etc.), para garantizar buena parte del éxito de todo lo programado. En realidad, lo que se pretende es implementar lo programado, atendiendo al buen funcionamiento del proceso, al seguimiento de las pautas diseñadas y al análisis de imprevistos/errores (positivos o negativos). Todo ello orientado a la toma de decisiones, lo que implica una elección entre diversas alternativas y la provisión de los recursos necesarios para el período inmediatamente posterior a la decisión. 
CAROLINA FERNÁNDEZ-SALINERO MIGUEL

UN ENFOQUE PEDAGÓGICO PARA EL DISEÑO DE PROGRAMAS DE FORMACIÓN EN CONTEXTOS ORGANIZATIVOS

\subsubsection{Seguimiento y control del proceso}

Durante el desarrollo del programa de formación, una tarea importante es garantizar su correcta evolución, mediante visitas, cuestionarios, entrevistas con los instructores, chequeo de la impartición con la programación establecida, observación, etc.

Los presupuestos básicos de esta fase serían:

1. Considerar el programa de formación como un diseño abierto de productos parciales.

2. Realizar una evaluación diagnóstica continua de las necesidades de la población afectada y de los efectos sobre el contexto de trabajo y el mercado laboral.

3. Mantener una actitud correctiva a lo largo del proceso de desarrollo.

4. Tener en el punto de mira el objetivo organizativo de manera constante.

5. Valorar periódicamente el programa realmente aplicado, sus costes y la evaluación de su calidad por parte de los formadores y de los participantes.

3.3.2. Revisión constante de las acciones (feedback)

Este proceso se efectúa a través de una estrategia continua de corrección, mediante el feedback entendido como retroalimentación, como información del estado en el que se encuentra el desarrollo del programa de formación, como medida de la discrepancia entre el estado actual y el previsto, como refuerzo, bien sea positivo bien sea negativo (Sarramona, Vázquez y Ucar, 1992, 105-106).

Desde esta perspectiva, la calidad en la ejecución del programa de formación está condicionada por la concurrencia de diversas variables: errores (gravedad, intensidad, frecuencia), tiempo transcurrido hasta su captación, tiempo consumido en la toma de decisiones, etc. En esta fase se debe verificar, por tanto, la eficacia del sistema de información existente y analizar los datos que permiten el cumplimiento puntual de las distintas etapas diseñadas, dada la elevada cantidad y complejidad de variables intervinientes y el significado económico, profesional, cultural, etc., de los posibles errores.

\subsubsection{Análisis de imprevistos}

Al plantearnos el seguimiento, control y revisión constante de la puesta en marcha del programa de formación es preciso considerar también la evaluación de los efectos imprevistos, sean o no deseables. 
Frecuentemente, desde una actitud escasamente racional, tiende a producirse una apropiación indebida de los resultados deseables, sin entrar en el examen de si son propiamente efectos, logros, esto es, resultados consiguientes a una acción intencional. Esta circunstancia hace necesaria una revisión constante de los efectos procedentes de la formación y, de manera especial, de los resultados imprevistos, ya sean de tipo positivo o negativo. Ambos tienen en común que han de ser explicados y que en torno a ellos debe generarse un compromiso personal, de confirmación en un caso y de corrección en el otro.

Si hablamos concretamente de los efectos no previstos, ¿la aparición de los mismos es debida a la potencialidad desbordante de nuestra actividad formativa, que supera todas las previsiones de resultados, o bien se debe a una programación incompleta o inadecuada de la misma? Porque el hecho de que en los programas se produzcan efectos no previstos no indica forzosamente que se trate de efectos "no previsibles". La respuesta al interrogante no es simple. Una línea de reflexión la proporciona la distinción ya apuntada entre resultados previstos de cariz deseable y no deseable (positivos y negativos si se prefiere), porque los segundos siempre pueden vincularse, en mayor o menor medida, con una programación inadecuada. Las técnicas más aplicadas para medir estos efectos no previstos son la aplicación de cuestionarios, las entrevistas abiertas, los debates colectivos y las observaciones directas.

\subsection{Evaluación del programa de formación}

La evaluación de la formación en las organizaciones es una fase más del proceso de programación global y, como tal, se encuentra influida por el resto de elementos que integran dicho proceso. Podemos definirla como:

El análisis del valor total de un sistema, de un programa o de un curso de formación, en términos tanto sociales como financieros [...]. La evaluación intenta valorar el coste-beneficio total de la formación y no únicamente la consecución de objetivos inmediatos (Kenney-Donnelly, 1972, 69).

Los propósitos básicos de la evaluación de la formación en la organización son, como Talbot y Ellis $(1969,145)$ señalan: determinar si los objetivos y contenidos de los programas formativos son coherentes con las necesidades detectadas, valorar si los objetivos fijados se están consiguiendo de la forma más efectiva y económica posible y, en su caso, identificar los cambios y modificaciones necesarios para su mejora. Hay que sumar a todo ello, como un objetivo de la evaluación, la mejora de los procesos de aprendizaje como vía de perfeccionamiento de la formación. Asimismo, los principios básicos en los que se sustenta su eficacia serían (Pineda, 1995, 53-54):

1. La mejora de la formación, no su aprobación o desaprobación. 
CAROLINA FERNÁNDEZ-SALINERO MIGUEL

UN ENFOQUE PEDAGÓGICO PARA EL DISEÑO DE PROGRAMAS DE FORMACIÓN EN CONTEXTOS ORGANIZATIVOS

2. La integración de la evaluación en el proceso de diseño del programa de formación.

3. El apoyo de la evaluación en una rigurosa identificación de las necesidades de formación y en un conjunto claro de objetivos, expresados, si es posible, en términos medibles.

4. La identificación y recogida de los principales costes implicados en la formación, examinando los beneficios con la máxima amplitud, desde los resultados inmediatos hasta los resultados diferidos y menos controlables.

5. La consecución de un diseño lo más riguroso y científico posible, siempre en la línea del análisis "antes, mientras y después".

6. La flexibilidad del proceso de valoración, que nos permita conocer efectos previstos y no previstos.

7. La participación de los alumnos, considerados como potenciales determinantes activos de acontecimientos y no como simples destinatarios pasivos de la formación.

Desde esta concepción y siguiendo la idea argumental de Pineda (2000, 121), la evaluación desempeña tres funciones básicas, las cuales justifican la necesidad y la importancia de su presencia:

- Una función pedagógica, consistente en verificar el proceso de consecución de los objetivos para mejorar la propia formación.

- Una función social, de certificar la adquisición de unos aprendizajes por parte de los participantes.

- Una función económica, centrada en identificar los beneficios y la rentabilidad que la formación genera en la organización.

Estas tres funciones se dirigen a alcanzar la finalidad última de la evaluación, aquella que le da sentido y determina todo el proceso evaluativo: la aportación de información que oriente la toma de decisiones y que conduzca a la introducción de mejoras formativas.

\subsubsection{Modalidades de evaluación de la formación}

Entre las fases que integran el proceso de programación y la evaluación de la formación se establecen relaciones constantes, las cuales nos permiten descubrir las modalidades de evaluación existentes en función de la finalidad que persiguen y del momento de su aplicación. Así, podemos identificar cinco modalidades de evaluación que son propias de la formación en contextos organizativos (Pineda, 2000, 122):

- Evaluación diagnóstica, centrada en el análisis de la coherencia pedagógica de la formación diseñada y en su adecuación a las necesidades de formación detectadas en la organización y en los participantes. 
- Evaluación formativa, que analiza la marcha del proceso de enseñanzaaprendizaje y el avance en el logro de los objetivos planteados.

- Evaluación sumativa, centrada en los resultados finales obtenidos por los participantes en términos de competencias alcanzadas al culminar la formación.

- Evaluación de la transferencia, que determina el grado en que los participantes transfieren o aplican a su puesto de trabajo los aprendizajes y las competencias alcanzadas con la formación.

- Evaluación del impacto, centrada en determinar las repercusiones que la formación tiene en la organización en términos de beneficios cualitativos y cuantitativos o monetarios, orientándose así a descubrir la rentabilidad económica de la formación para la compañía.

Entre estas cinco modalidades se da una interdependencia mutua, ya que un proceso de evaluación exhaustivo ha de contemplar todas ellas y utilizar de manera sistémica la información que emerja de cada una.

\subsubsection{Modelo holístico de evaluación de la formación}

El modelo holístico de evaluación de la formación que plantea Pineda (2000, 122-124) nos parece el más acertado actualmente y, por ello, vamos a basarnos en él para identificar la estructura esencial que debe incluir la evaluación formativa en las organizaciones.

Este modelo permite establecer el diseño de un plan de evaluación sistemático, riguroso y coherente que tenga en cuenta las funciones mencionadas y que aplique las modalidades señaladas. Es un modelo que pretende responder a cinco interrogantes básicos que afectan a la evaluación de forma integrada, cruzando las respuestas y elaborando un engranaje de estrategias evaluativas que cubran la totalidad del proceso de formación. Los interrogantes son:

1. ¿Para quién evalúo? ¿Quién es el destinatario de mis evaluaciones?, ¿quién es mi cliente? La respuesta a este interrogante determina la finalidad y el enfoque del proceso de evaluación que diseñamos. El destinatario puede ser desde la propia organización, hasta el departamento de formación, pasando por el formador, el participante, el cliente interno y/o externo, los agentes sociales, etc.

2. ¿Qué evalúo? ¿Qué elementos y aspectos quiero evaluar?, ¿cuál es el objeto de mi evaluación? Aquí identificamos seis niveles básicos de evaluación que se pueden desglosar en subniveles hasta llegar a los elementos específicos ${ }^{7}$ :

7. Para la identificación de estos niveles nos hemos basado en los modelos de evaluación de: KirkPatrick (1967) y Hamblin (1974), así como en el de Phillips (1990), en el de Wade (1994) y en el de WARR, BIRD y RAKHAM (1976). 

EN CONTEXTOS ORGANIZATIVOS

- Nivel 1: Satisfacción del participante con la formación.

- Nivel 2: Logro de los objetivos de aprendizaje por los participantes.

- Nivel 3: Coherencia pedagógica del proceso de formación.

- Nivel 4: Transferencia de los aprendizajes al puesto de trabajo.

- Nivel 5: Impacto de la formación en los objetivos de la organización.

- Nivel 6: Rentabilidad de la formación para la organización.

3. ¿Quién evalúa? ¿Cuáles son los agentes de la evaluación? Dichos agentes deberían ser todos aquellos afectados por la formación, desde el participante hasta la dirección de la organización, pasando por el formador, el departamento de formación, el superior del participante, sus compañeros, los clientes, etc.

4. ¿Cuándo evalúo? ¿En qué momento es conveniente evaluar? La respuesta a esta cuestión son los cuatro momentos básicos que se corresponden con las modalidades clásicas de la evaluación:

- Antes de iniciar la formación: Evaluación inicial o diagnóstica.

- Durante la formación: Evaluación procesual o formativa.

- Al concluir la formación: Evaluación final o sumativa.

- Con posterioridad a la finalización de la formación: Evaluación diferida, de transferencia e impacto.

5. ¿Cómo evalúo? ¿Con qué instrumentos puedo evaluar todo lo anterior? La respuesta aquí es amplia y variada, puesto que la posibilidad de instrumentos es ilimitada. Podemos utilizar cuestionarios, entrevistas individuales y grupales, controles y tests finales, actividades y productos de aprendizajes, observaciones sistemáticas, demostraciones, informes de evaluación, indicadores cualitativos y cuantitativos del impacto, etc.

La introducción en las organizaciones de un modelo de estas características puede resultar una herramienta de gran utilidad para el departamento de formación, una herramienta que facilite la compleja tarea de la evaluación, especialmente en la dimensión del impacto, que es la que presenta más deficiencias en la mayoría de organizaciones.

\subsubsection{De la evaluación de la formación a la auditoría de la formación}

Como complemento a lo anteriormente señalado sobre evaluación de la formación, conviene realizar a continuación un breve análisis de un concepto de evaluación actual que engloba todo lo precedente y que amplía el significado del término evaluación formativa. El concepto mencionado es el de auditoría de formación.

Para su definición vamos a seguir a una autora experta en el tema, Pilar Pineda, quien en su obra de 1995 (p. 81), La auditoría de formación, nos dice: 
Entendemos por auditoría de formación un análisis metódico, es decir, función por función, actividad por actividad y medio por medio, de las actividades formativas que se dan en el seno de una empresa. Este análisis se basa en criterios explícitos $y$, mediante el establecimiento de indicadores, pone en evidencia las diferencias, disfunciones y contradicciones observadas en ellos, en relación con referenciales previamente fijados. El análisis conduce a la emisión de recomendaciones y propuestas operativas en forma de informe final, en el que se exponen los puntos fuertes y débiles, las causas y las acciones a adoptar para mejorar la realidad auditada.

Sin querer ser exhaustivos, vamos a perfilar a continuación algunas de las características básicas de la auditoría de formación, que nos permitan constatar su importancia en el desarrollo de procesos de valoración, globales y precisos, para el adecuado y cada vez más complejo ámbito organizativo. Las características mencionadas son, siguiendo a Le Cointe y Rebinguet (1990), así como a Le Boterf et al. (1985):

1. Analiza la función formativa desde una perspectiva global, integral.

2. Intenta poner en evidencia los hechos, sus causas y la pluralidad de puntos de vista que los acompañan.

3. Tiende a poner de manifiesto a los actores el significado de los fenómenos que integran su vida cotidiana, ayudándoles en su comprensión.

4. Se basa en la explicitación y en la confrontación de interpretaciones.

5. Implica la participación de los actores en las diferentes etapas del proceso auditor.

6. Es un procedimiento educativo al ser participativa.

7. Se caracteriza por su relatividad, ya que sus resultados dependen del momento de su aplicación, de su duración, de las competencias de los auditores y del grado de participación de los auditados.

8. Mide y hace estimaciones según unos criterios normativos, para identificar los problemas y los efectos no previstos.

9. Los fenómenos que la auditoría escucha y observa pertenecen al presente, pero ello no quita que esté atenta también a las resonancias del pasado, así como a las proyecciones del futuro.

10. Identifica las disfunciones y las relaciones de coherencia o incoherencia con las políticas establecidas, así como la pertinencia de éstas.

11. Tiene siempre un sentido optimizador, ya que a través del control ejercido se detectan problemas e incorrecciones, pero emitiendo siempre explicaciones causales de los mismos que posibiliten la proposición de medidas de mejora reales. 


\section{A MODO DE CONCLUSIÓN}

El diseño de un programa de formación se convierte, en definitiva, en una labor de gestión del conocimiento con tres metas globales: generar el desarrollo y optimización de la organización, favorecer un adecuado clima de trabajo y potenciar las competencias personales, profesionales y laborales de las personas que conforman el equipo humano de la organización. Con tal misión debe fomentarse la implicación de todos los niveles de la organización, tanto la Dirección, como el personal de línea, los jefes inmediatos y los empleados; existiendo una auténtica comunicación entre todos ellos, tanto si se constituyen en organizadores de la formación como si son participantes en la misma. Este conjunto de actividades debe ser promovido desde el Departamento de Recursos Humanos, Personal o Formación y ha de convertirse en una tarea habitual dentro de la organización.

En cuanto a la estructura de un programa de formación, resulta fundamental no olvidar la secuencia analizada, es decir: identificar el programa de formación a realizar, sus ventajas e inconvenientes; detectar y priorizar las necesidades más relevantes; implicar este proceso en los objetivos estratégicos de la organización, siempre desde una perspectiva de resultados positivos; formular los objetivos a alcanzar; programar operativamente los contenidos, las modalidades y el método; identificar a los gestores de la formación, controlar la organización (condiciones, lugares y tiempos), la duración de los programas, el presupuesto necesario y los recursos disponibles y requeridos; establecer las líneas de ejecución, manteniendo un seguimiento constante del proceso de desarrollo, un control riguroso y un análisis de los imprevistos; evaluar el programa, considerando la evaluación como un análisis continuo y constante de la programación realizada. El diseño de un programa así concebido abre una puerta a la formación como instrumento de cambio y mejora y orienta la política estratégica hacia la "organización autocualificante", aquella que busca en el conocimiento y en el aprendizaje las herramientas para el progreso y la competitividad.

\section{BiBLIOGRAFÍA}

BARREDA, R. (1995) La función de educación en la organización moderna. Madrid, Conorg. Buckley, R. y CAPLE, J. (1991) La formación. Teoria y práctica. Madrid, Díaz de Santos.

Burge, E. J. y Frewin, C. C. (1985) Self-directed learning in distance learning, en HusÉN, T. y POSTLETHWAITE, T. N. (eds.). The International Encyclopedia of Education. Research and Studies, 8 (S). Oxford, Pergamon Press, 4515-4517.

Castillejo, J. L.; Sarramona, J. y Vázquez, G. (1988) Pedagogía Laboral, Revista Española de Pedagogia, 46 (181), 421-440.

Colom, A.; Sarramona, J. y VÁzquez, G. (1991) Trabajo y empresa, en Núñez Cubero, L. (ed.). Educación y Trabajo. Sevilla, Preu-Spínola, 33-62.

- (1994) Estrategias de formación en la empresa. Madrid, Narcea. 
CAROLINA FERNÁNDEZ-SALINERO MIGUEL

UN ENFOQUE PEDAGÓGICO PARA EL DISEÑO DE PROGRAMAS DE FORMACIÓN EN CONTEXTOS ORGANIZATIVOS

De KeTEle, J. M. et al. (1988) Guide du formateur. Bruselas, De Boeck.

FERNÁNDEZ-SALINERO, C. (1999) El diseño de un plan de formación como estrategia de desarrollo empresarial: Estructura, instrumentos y técnicas, Revista Complutense de Educación, 10 (1), 181-242.

FERRÁNDEZ, A. y VILADOT, G. (2002a) Las necesidades de formación laboral en las PYMES. Oviedo, Septem Ediciones.

- (2002b) Modalidades de formación en las organizaciones, en PINEDA, P. (coord.). Gestión de la formación en las organizaciones. Barcelona, Ariel, 115-148.

- (1994) La formación de adultos en la empresa. Madrid, Fondo Formación.

Font, À. e ImBERnón, F. (2002) Análisis de necesidades de formación. Analizar y detectar necesidades para una coherente planificación, en PINEDA, P. (coord.). Gestión de la formación en las organizaciones. Barcelona, Ariel, 37-61.

Gan, F.; Alonso, B.; Francisco, E. y PuYOL, S. (1995) Manual de técnicas e instrumentos de formación en la empresa. Barcelona, Apóstrofe.

GoldsteIn, I. L. (1986) Training in organizations. California, Brooks-Cole.

Griffin, V. R. (1985) Self-directed learning: Theories, en HusÉN, T. y Postiethwarte, T. N. (eds.). The International Encyclopedia of Education. Research and Studies, 8 (S). Oxford, Pergamon Press, 4516-4519.

Gros, B. (1993) Las nuevas tecnologías de la información, en TriLla, J. La educación fuera de la escuela. Ámbitos no formales y educación social. Barcelona, Ariel, 159-185.

Hamblin, A. C. (1974) Evaluation and control of training. Maidenhead (UK), McGraw Hill.

Hellouin, V. (coord.) (1995) Construire un plan de formation, Actualité de la Formation Permanente, 136 (mai-juin). Monográfico.

KEEGAN, D. (1990) Formation of distance education (second edition). London, Routledge.

KENNEY, J. y DONNELLY, P. (1972) Manpower training and development. Londres, Harrap.

KIRKPATRICK, D. L. (1967) Evaluation of training, en CARIG y BITTLE (eds.). Training and development handbook. New York, McGraw Hill.

LE BOTERF, G. (1991) Ingeniería y evaluación de los planes de formación. Bilbao, Deusto.

LE BOTERF, G. et al. (1991) Cómo invertir en formación. Barcelona, Ediciones Gestión 2000.

- (1993) Cómo gestionar la calidad de la formación. Barcelona, Ediciones Gestión 2000.

Le Boterf, G.; Dupouey, P. y Viallet, F. (1985) L'audit de la formation professionnelle. Paris, Les Éditions d'Organisation.

Le Cointe, M. y Rebinguet, M. (1990) L'audit de l'établissement scolaire. Paris, Les Éditions d'Organisation.

LYNCH. J. J. (1968) Making manpower effective Part 1. London, Pan Books.

MARTíNeZ MUT, B. (1994) Reingeniería de la evaluación de programas de formación, Teoría de la Educación. Revista Interuniversitaria, 6, 199-219.

- (2002) Calidad en las organizaciones y formación, en Pineda, P. (coord.). Pedagogía laboral. Barcelona, Ariel, 173-200.

MÉNDEZ, E. (2002) Aspectos clave a considerar en el diseño de programas formativos, Capital Humano, 160, 124-126.

Moore, M. G. (1990) Management of distance learning, en HuséN, T. y PostlethwaIte, T. N. (eds.). The International Encyclopedia of Education. Research and Studies, Suplementary Volume Two. Oxford, Pergamon Press, 168-171.

PHILlIPS, J. J. (1990) Training evaluation and measurement methods. London, Kogan Page.

Pineda, P. (1995) Auditoría de la formación. Barcelona, Gestión 2000.

- (2000) Evaluación del impacto de la formación en las organizaciones. Educar, 27, 119-133. 
CAROLINA FERNÁNDEZ-SALINERO MIGUEL UN ENFOQUE PEDAGÓGICO PARA EL DISEÑO DE PROGRAMAS DE FORMACIÓN EN CONTEXTOS ORGANIZATIVOS

- (coord.) (2002a) Gestión de la formación en las organizaciones. Barcelona, Ariel.

- (2002b) Pedagogía Laboral. Barcelona, Ariel.

PraTT, D. (1989) Cybernetics and curriculum, en LEWY, A. (ed.). The International Encyclopedia of Curriculum. Oxford, Pergamon Press, 42-46.

Puchol, L. (1995) Dirección y gestión de recursos bumanos (2 edición revisada y actualizada). Madrid, ESIC.

REIG, E.; FERNÁNDEZ, J. y JAULí, I. (2003) Los recursos bumanos en las organizaciones orientadas a la eficacia y el aprendizaje. Madrid, Thomson.

SÁNchez Cerezo, S. (dir.) (1991) Tecnología de la educación. Léxicos de Ciencias de la Educación. Madrid, Santillana.

SARRAMONA, J. (1986) Sistemas no presenciales y tecnología educativa, en CASTILLEJO, J. L. et al. Tecnología y Educación. Barcelona, Ceac, 113-123.

- (2002) La formación continua laboral. Madrid: Biblioteca Nueva.

SARRAMONA, J.; VÁzQuez, G. y UCAR, X. (1992) Evaluación de la educación no formal, en SARRAMONa, J. (ed.). La educación no formal. Barcelona, Ceac, 91-120.

SCHEIN, E. H. (1988) La cultura empresarial y el liderazgo. Una visión dinámica. Barcelona, Plaza y Janés.

SENGE, P. (1992) La quinta disciplina. Barcelona, Granica.

SOlÉ, F. y Mirabet, M. ${ }^{a}$ (1994) Cómo confeccionar un plan de formación en una empresa. Barcelona, La Llar del Llibre.

- (1997) Guía para la formación en la empresa. Madrid, Cívitas.

STUFFLEBEAM, D. L. y SHINKFIELD, A. J. (1987) Evaluación sistemática. Guía teórica y práctica. Barcelona, Paidós-MEC.

TALBOT, J. R. y ElLIS, C. D. (1969) Analysis and costing company training. London, Gower Press.

TRES Viladomat, J. (2002) Diseño de programas de formación en las organizaciones, en PiNEDA, P. (coord.). Gestión de la formación en las organizaciones. Barcelona, Ariel, 93-113.

UCERO, J. M. (1997) El plan de formación en la empresa. Madrid, ESIC. Seminario celebrado en Madrid, el día 12 de diciembre.

VENTURA, J. (coord.). (2003) Capital intelectual y aprendizaje organizativo: Nuevos desafíos para la empresa. Madrid, AENOR.

VILADOT, G. (2002) Métodos y técnicas de formación en las organizaciones, en PINEDA, P. (coord.). Gestión de la formación en las organizaciones. Barcelona, Ariel, 149-169.

WADE, P. (1994) Measuring the impact of training. Londres, Kogan Page.

WARR-BIRD-RACKHAM (1976) Evaluation of management training. Londres, Gower Press. 